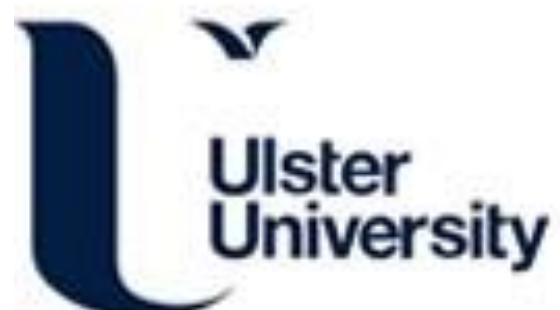

Interseismic coupling, stress evolution, and earthquake slip on the Sunda Megathrust

Nalbant, S., McCloskey, J., Steacy, S., NicBhloscaidh, M., \& Murphy, S. (2013). Interseismic coupling, stress evolution, and earthquake slip on the Sunda Megathrust. Geophysical Research Letters, 40(16), 4204-4208. https://doi.org/10.1002/grl.50776

Link to publication record in Ulster University Research Portal

\section{Published in:}

Geophysical Research Letters

Publication Status:

Published (in print/issue): 28/08/2013

DOI:

10.1002/grl.50776

\section{Document Version}

Publisher's PDF, also known as Version of record

\section{General rights}

Copyright for the publications made accessible via Ulster University's Research Portal is retained by the author(s) and / or other copyright owners and it is a condition of accessing these publications that users recognise and abide by the legal requirements associated with these rights.

\section{Take down policy}

The Research Portal is Ulster University's institutional repository that provides access to Ulster's research outputs. Every effort has been made to ensure that content in the Research Portal does not infringe any person's rights, or applicable UK laws. If you discover content in the Research Portal that you believe breaches copyright or violates any law, please contact pure-support@ulster.ac.uk. 


\title{
Interseismic coupling, stress evolution, and earthquake slip on the Sunda megathrust
}

\author{
Suleyman Nalbant, ${ }^{1}$ John McCloskey, ${ }^{1}$ Sandy Steacy, ${ }^{1}$ Mairead NicBhloscaidh, ${ }^{1}$ and \\ Shane Murphy ${ }^{1}$ \\ Received 14 May 2013; revised 12 July 2013; accepted 19 July 2013; published 20 August 2013.
}

[1] The extent to which interseismic coupling controls the slip distribution of large megathrust earthquakes is unclear, with some authors proposing that it is the primary control and others suggesting that stress changes from previous earthquakes are of first-order importance. Here, we develop a detailed stress history of the Sunda megathrust, modified by coupling, and compare the correlation between slip and stress with that of slip versus coupling. We find that the slip distributions of recent earthquakes are more consistent with the stress field than with the coupling distributions but observe that in places, the stress pattern is strongly dependent on poorly constrained values of slip in historical earthquakes. We also find that of the 13 earthquakes in our study for which we have hypocentral locations, only two appear to have nucleated in areas of negative stress, and these locations correspond to large uncertainties in the slip distribution of pre-instrumental events. Citation: Nalbant, S., J. McCloskey, S. Steacy, M. NicBhloscaidh, and S. Murphy (2013), Interseismic coupling, stress evolution, and earthquake slip on the Sunda megathrust, Geophys. Res. Lett., 40, 4204-4208, doi:10.1002/grl.50776.

\section{Introduction}

[2] Advance knowledge of the likely area and approximate slip distribution of large subduction zone earthquakes would be very useful for hazard analysis. Clearly, these factors strongly affect the shaking but they also control the size of any triggered tsunami. In Sumatra, for instance, large slips beneath deep water are the main reason that the $M=9.2$ 2004 earthquake produced tsunami runup of greater than $30 \mathrm{~m}$ in the Aceh province [Geist et al., 2006]. By contrast, runup from the $M=8.7$ Simeulue-Nias earthquake did not exceed $4 \mathrm{~m}$, primarily because the main seafloor displacement was in much shallower water [Geist et al., 2006].

[3] Recently, a number of authors [e.g., Chlieh et al., 2008; Moreno et al., 2010; Lorito et al., 2011] have suggested that variations in coupling along a subduction zone may provide information about the areas likely to experience large slips. Coupling indicates the degree to which long-term slip rates are accommodated by interseismic creep [Burgmann et al., 2005]; where coupling is low, this is the dominant mechanism, whereas seismic processes

Additional supporting information may be found in the online version of this article.

${ }^{1}$ School of Environmental Sciences, University of Ulster, Coleraine, UK.

Corresponding author: S. Steacy, University of Ulster, Cromore Road, Coleraine, BT54 6NX, UK. (s.steacy@ulster.ac.uk)

C2013. American Geophysical Union. All Rights Reserved. 0094-8276/13/10.1002/grl.50776 dominate when coupling is high. Hence, stress accumulation is heterogeneous; completely locked areas build up stress at the plate convergence rate, whereas those with weaker coupling accumulate stress at a lower rate [e.g., Chlieh et al., 2008].

[4] One region where the coupling has been extensively studied is along the Sunda Trench Sumatra. Here, Chlieh et al. [2008] used 110 geodetic and paleogeodetic measurements to compute the interseismic coupling along the subduction zone. Their results as well as the locations of $M \geq 7$ earthquakes from 1797 to 2002 are shown in Figure 1; a coupling coefficient of 1 indicates that the interface is completely locked, whereas coupling of 0 means that there is no interseismic accumulation of slip deficit.

[5] Sumatra experienced $3 M \geq 8.5$ earthquakes between 1797 and 1861, and the areas of these events seem to correspond well with the regions of high coupling [Chlieh et al., 2008]. Specifically, the 1797 and 1833 events primarily ruptured the highly coupled regions in the Mentawai Islands, whereas the northern portion of the 1861 earthquake occurred in the region of high coupling near Nias Island (Figure 1). Further, the latter reruptured in the $2005 M=8.7$ Nias earthquake which overlapped the 1861 event but extended further north.

[6] The correspondence between coupling and slip in the 2007 earthquakes is less clear, however (Figure 2). These $M=8.4$ and $M=7.9$ events occurred near the Mentawai Islands on 12 September and were followed by an $M=7.1$ earthquake the following day. Despite occurring in an overall zone of high coupling, the first two events appear to have ruptured discrete asperities [Konca et al., 2007] with areas that experienced high slip in the 1833 earthquake appearing to act as barriers in 2007. Two possible explanations for this are that the asperities are separated by a zone of low coupling below the resolution of the (paleo)geodetic data or that there was low prestress in the intervening zone due to high slip in the 1833 earthquake [Konca et al., 2007].

[7] Low prestress has also been suggested to explain the lack of correlation between slip and high coupling on a portion of the rupture plane of the $2010 M=8.8$ Maule earthquake. Moreno et al. [2010] compared three preliminary slip distributions with the interseismic coupling and concluded that there was a good correspondence between two areas of high coupling and high slip as well as one of low coupling and low slip. However, they noted that both ends of the rupture terminated in zones of high coupling and suggested that this was due to low prestress resulting from previous earthquake slip.

[8] Lorito et al. [2011] also compared the coupling in the Maule region to the slip, in this case, to a more sophisticated model derived from GPS and tsunami data. In contrast to Moreno et al. [2010], they found little correlation between 


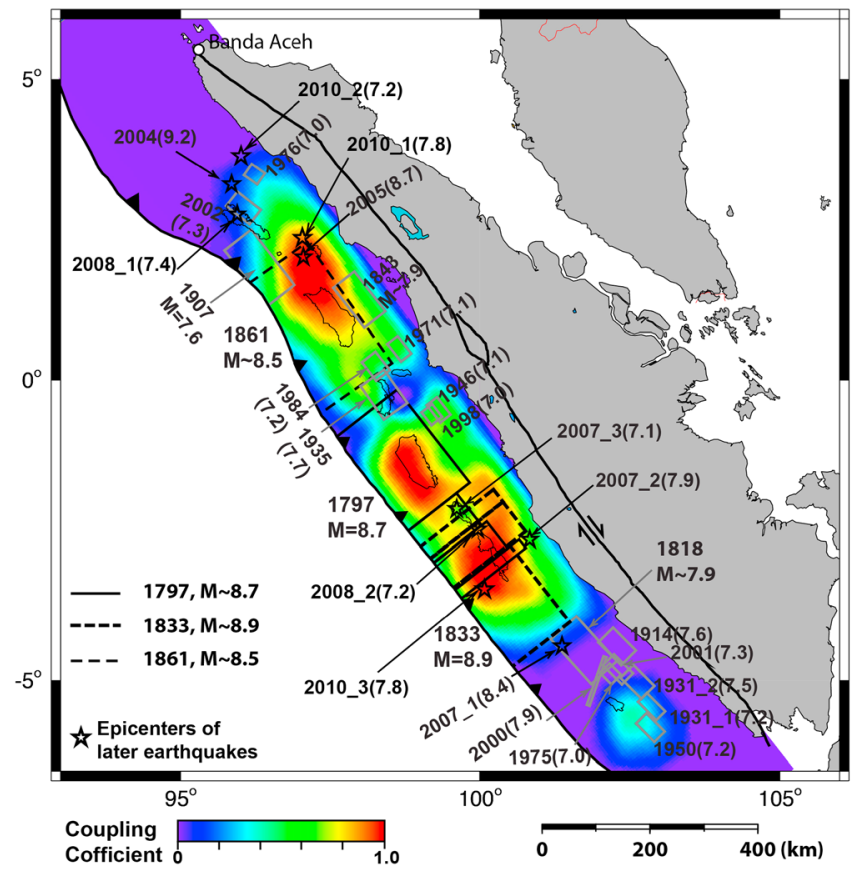

Figure 1. Coupling coefficients [Chlieh et al., 2008] and the locations of $M \geq 7$ earthquakes between 1797 and 2007. Red indicates areas of high coupling, whereas purple regions have zero coupling and hence do not accumulate stress. Rectangular boxes indicate source dimensions of modeled earthquakes: black boxes the 1797, 1833, and 1861 events, and gray other events prior to 2004. Stars indicate the epicenters of post 2003 events; slip distributions of events of interest are shown in later figures, and the islands are named in Figure 2.

the seismic coupling and the slip and, further, observed that the highly coupled region with largest slip deficit (their "Darwin gap") experienced relatively small slip in the earthquake. They concluded that coupling on its own provides a poor forecast of future slip, and hence, other factors, including multicycle slip histories, must be important.

[9] The work described above suggests that both coupling and previous stress history may be important in estimating possible high-slip areas in future subduction earthquakes. However, as Lorito et al. [2011] point out, this history involves much more than relaxation from the most recent nearby earthquake and must, at minimum, include plate tectonic loading, stress relaxation due to earthquake slip, and coseismic stress changes. Postseismic stress changes due to afterslip and/or poroelastic/viscoelastic relaxation may also be important.

[10] In this paper, we assess the importance of the slip history and its resulting stress field as well as coupling on the slip distributions of recent events along the Sunda Trench offshore Sumatra. To accomplish this, we reconstruct the history of stress accumulation and release along the subduction zone beginning from a baseline of 1797 . We choose this area because of the availability of data on its long-event history as well as information on coupling and interseismic loading.

\section{Methods}

[11] In order to calculate the stress prior to the occurrence of any earthquake of interest, we need three pieces of information: the slip distributions of the events which preceded it, the interseismic loading rate, and the coupling coefficients. The coupling data are provided by Chlieh et al. [2008] and are used here as a linear multiplier for both coseismic and interseismic stresses. The latter is clearly consistent with our understanding of coupling as interseismic stress would not be expected to increase in regions not accumulating slip deficit. The application to coseismic stress changes is less clear; here, we are assuming that the subduction interface responds similarly to stress steps as it does to slower tectonic loading. Hence, in our model, no stress (coseismic or interseismic) accumulates where the coupling coefficient is zero.

[12] Twenty nine $M \geq 7$ earthquakes were recorded in the study area from 1797 to 2010 . Two early events, the $1797 M=8.5-8.7$ and $1833 M=8.6-8.9$, were studied extensively by Natawidjaja et al. [2006], and hence, slip distributions are available. These are based on inversions of coral data which are uplifted in large events and experience dieback when exposed above sea level. The corals are clustered along the offshore islands, and hence, the accuracy of the slip distributions is limited away from these features. This is a particular issue for the 1833 event as we use their preferred model which has $18 \mathrm{~m}$ of slip extending from the northern end of South Pagai island (approximately $-3.1^{\circ}$ ) to as far south as about $-5^{\circ}$ [Natawidjaja et al., 2006, Figure 26]; however, the coral data is all north of $-3.5^{\circ}$.

[13] We estimate the locations and magnitudes of the 1818 and 1843 events based on the tsunami inundation areas given by Newcomb and McCann [1987]. From comparison with modern earthquakes, we assume that the 1818 earthquake had a magnitude of at least $M=7.9$. It could be larger than this but not smaller, and our results are not sensitive to uncertainties involved with this event. Similarly, we estimate the magnitude of the 1843 event to be at least $M=7.8$. We

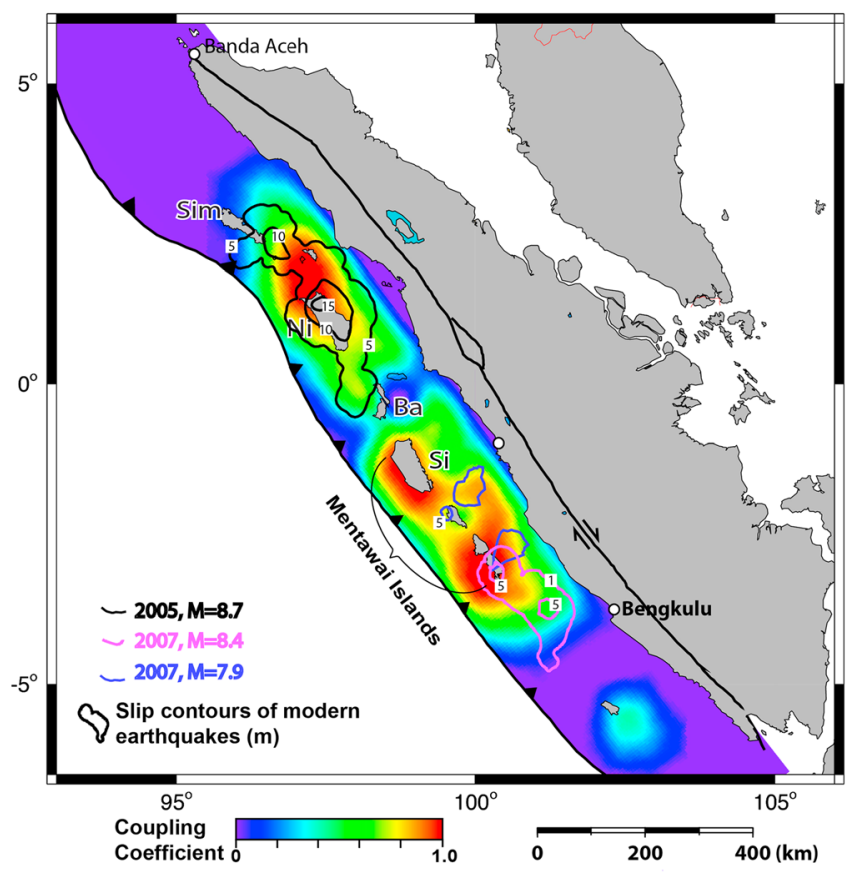

Figure 2. Slip distributions of the 2005 and two largest 2007 earthquakes [Konca et al., 2007] superposed on the coupling distribution from Chlieh et al. [2008]. The major islands are abbreviated as Sim (Simelue), Ni (Nias), Ba (Batu), and Si (Siberut). 


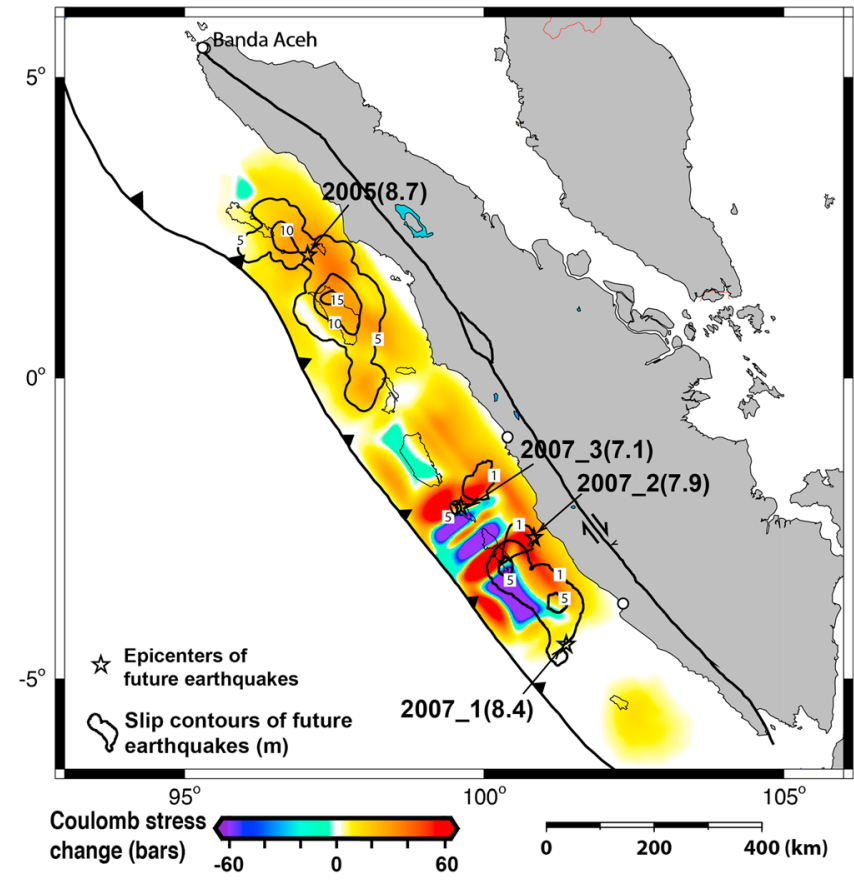

Figure 3. Coseismic and interseismic stress changes from a baseline of zero stress immediately prior to the occurrence of the 1797 earthquake. Note the areas of large negative stress; the northern two are in places that experienced $11 \mathrm{~m}$ of slip in the 1833 earthquake, whereas the southern patch is in a region that had $18 \mathrm{~m}$ of slip in that event [Natawidjaja et al., 2006].

choose the upper end of the magnitude range $(M=8.3-8.5)$ from Newcomb and McCann for the 1861 earthquake as this is the preferred value of Natawidjaja et al. [2006] and others; we estimate the location from the tsunami inundation.

[14] Earthquake magnitudes and locations for the events from 1907-1984 are taken from Newcomb and McCann [1987]; those for events from 1998-2002, the $M=7.1$ in 2007, and the 2008 earthquakes are from the U.S. Geological Survey. For these earthquakes, as well as the three described in the preceding paragraph, we use the empirical relations of Wells and Coppersmith [1994] to estimate the lengths, widths, and average slips. We apply a triangular taper to the slip distributions to eliminate unphysical edge effects while preserving the average slip; this has the effect of increasing the magnitude of the slip in the center of the rupture. We assume that the length and width of each earthquake is symmetrical around its hypocenter. Data for larger modern events come from a variety of sources including Ji (available at http://www.geol. ucsb.edu/faculty/ji/big_earthquakes/home.html), Konca et al. [2007], and the rapid solutions from Hayes (http://earthquake.usgs.gov/earthquakes/eqinthenews/).

[15] From the slip distributions, we compute coseismic stresses on the subduction zone in the study area between $-6.5^{\circ}$ to $4.0^{\circ}$ latitude and $95.8^{\circ}$ to $103^{\circ}$ longitude. The interface is assumed to have a uniform strike of $222^{\circ}$, dip $15^{\circ}$, and stresses are resolved for a rake of $90^{\circ}$; we choose constant values in order to avoid features in the stress field related solely to changes in geometry. We assume an effective coefficient of friction of 0.4 as this is a common value in the literature; however, our results are insensitive to this choice as shear stress changes dominate on the subduction interface.
[16] Interseismic (secular) stress accumulation is computed from the movement of the Indo-Australian plate relative to the Sunda Plate; this is oblique, $\mathrm{N} 15^{\circ} \mathrm{E}$, with a rate of about $57 \mathrm{~mm} / \mathrm{yr}$ [Bock et al., 2003]. A large portion of the plate motion is translated into nearly perpendicular thrusting on the Sunda megathrust at $45 \mathrm{~mm} / \mathrm{yr}$ [Subarya et al., 2006]; we assume that this rate is constant on the megathrust west of Sumatra. To compute the interseismic loading rate, we use the boundary element method of Gomberg and Ellis [1994]. We first construct a model of the subduction interface and assume it is a freely slipping boundary. We then apply the regional strain rate, the interface slips in response, and from this, we compute an interseismic stressing rate of $0.14 \mathrm{bars} / \mathrm{yr}$. The stress field prior to the occurrence of each earthquake of interest is then the sum of the coseismic and interseismic stress changes from our baseline date of immediately before the 1797 event.

\section{Results}

[17] Our main results are in shown in Figure 3 where we plot the total stress field immediately prior to the 2005 Nias earthquake and overlay it with slip contours of that event as well as those of the two largest earthquakes in 2007 . Note that the latter events are sufficiently distant from the 2005 earthquake that coseismic stress changes were negligible while the interseismic stress accumulation between 2005 and 2007 was only 0.28 bar; this does not affect the results.

[18] To the north, the correspondence between slip in the 2005 earthquake and both the stress field and the coupling (Figure 2) is quite clear. In general, the highest slip occurred where the coupling is greatest although there are some discrepancies. For example, at the northern end of the rupture, a portion of the $>10 \mathrm{~m}$ slip occurred in a zone of only moderate coupling; however, the stress in the area was higher than in nearby locations experiencing less slip. Additionally, the $>5$ $m$ slip contour to the northeast extends into a region of quite low coupling but this may be explained by the stress which is on the order of 10 bars. At the southern end of the rupture, the lobe of $>5 \mathrm{~m}$ slip appears to correspond well with a zone of moderate stress.

[19] The slip distributions of the two largest 2007 earthquakes to the south are more complex. The first $M=8.4$ event began in a region of very low coupling although the stress was about 10 bars. It experienced $>5 \mathrm{~m}$ of slip in two patches, one situated in a region of high coupling, the other in one of moderate coupling. Coupling coefficients in the intervening area range from about 0.5 adjacent to the latter patch to nearly 1 next to the other lobe. However, the stress between the patches is complicated, with negative values updip and quite high positive ones downdip. The rupture terminated to the north in a region of negative prestress but high coupling. The subsequent $M=7.9$ earthquake initiated very close to the termination of the $M=8.4$ event. It experienced $>1 \mathrm{~m}$ of slip in that area then jumped approximately $100 \mathrm{~km}$ northward, with the intervening area experiencing little coseismic slip [Konca et al., 2007]. This zone is highly coupled, but the stress was very strongly negative due to large slip in the 1833 earthquake.

[20] The stress immediately prior to each earthquake resolved onto either its rupture plane or hypocentral location is given in Table $\mathrm{S} 1$ in the supporting information, and snapshots of the stress field prior to the occurrence of events 


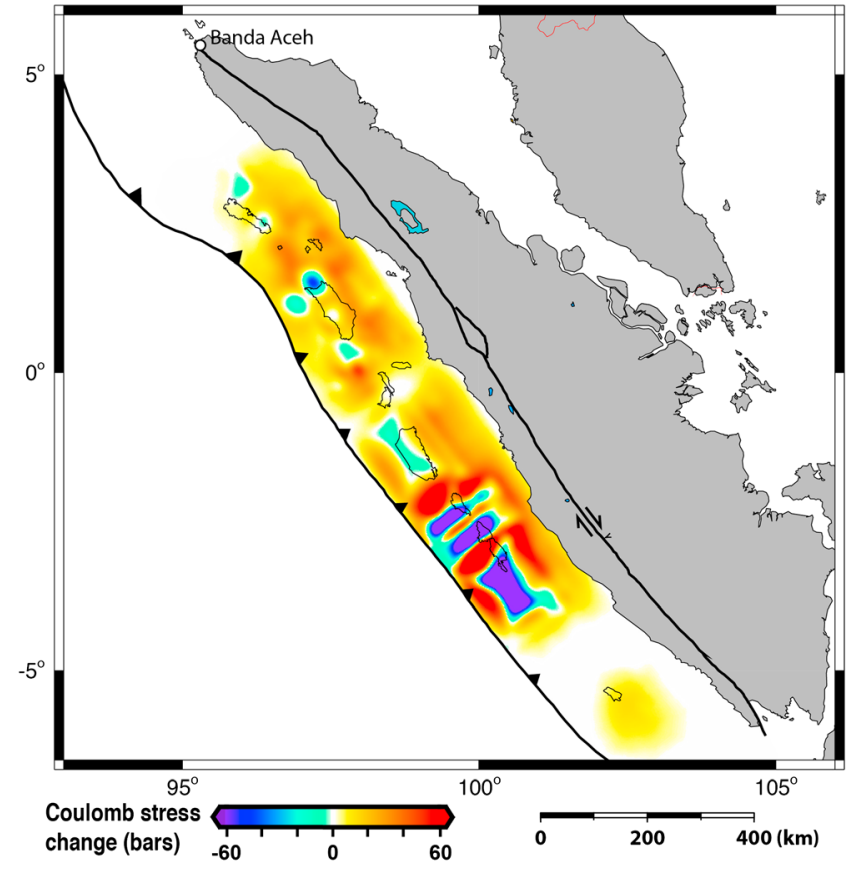

Figure 4. The state of stress as of the end of 2012, note large stresses immediately south of Siberut Island (from approximately $-2^{\circ}$ ) suggestion the potential for a further large earthquake.

of interest are shown in Figure S1. For completeness, we include coseismic and total (coseismic + interseismic) stress and show results modified and unmodified by the coupling coefficients. Of the 15 events for which hypocenters are not known, all had areas of positive stress on their rupture planes. Additionally, only one had significant negative stress - this was the 1833 earthquake in the portion that overlapped with the 1797 event.

[21] We have hypocentral locations for the 13 earthquakes which occurred from 1998 onward. Eight of these experienced positive stress at the hypocentre, two zero stress (because the coupling coefficient is believed to be zero at those points [Chlieh et al., 2008]), one occurred on the rupture plane of an earthquake that occurred earlier in the same year, and two had negative prestress at their hypocenters. Those events, the $M=7.22008$ and $M=7.72010$ earthquakes, nucleated in areas that respectively experienced $11 \mathrm{~m}$ and $18 \mathrm{~m}$ of slip in the 1833 event [Natawidjaja et al., 2006]. Note that two events, the $M=8.72005$ and $M=7.8$ 2010 earthquakes had negative coseismic stresses at their hypocentral locations, but with the addition of interseismic stress accumulation, the total stress fields were positive.

[22] The stress (from the 1797 baseline) at the end of 2012 is shown in Figure S2. By comparison with Figure 3, it can be seen that the 2007 and 2008 earthquakes released little of the accumulated stress near the Mentawai Islands. Hence, we find that the potential for a further large damaging earthquake in that region remains high, a conclusion also reached by Konca et al. [2007] based on its slip history.

\section{Discussion and Conclusions}

[23] Our main result is that, at least qualitatively, there is a better correspondence between slip in the 2005 and 2007 earthquakes and the total stress field modified by coupling than between slip in those events and coupling on its own. This agrees with the suggestion of Lorito et al. [2011] that other factors such as detailed stress history are likely to be important. However, the result is somewhat surprising due to the large uncertainties in the stress calculations.

[24] For instance, we begin the calculations from a baseline of zero stress immediately prior to the 1797 event. Clearly, this is incorrect-had there been no stress at that time, the earthquake could not have occurred. However, some baseline needs to be posited and going further back in time without corresponding information on coseismic stress changes would be even less accurate. It may be that our starting point is far enough in the past that inaccuracies due to the zero baseline are largely masked by subsequent coseismic and interseismic stress changes.

[25] More importantly, there are several inaccuracies in the slip distributions which, in turn, control the coseismic stress changes. First, the locations and magnitudes of the majority of the earthquakes are not well constrained and the slip is based on empirical relations which may or may not be accurate. Further, we apply a triangular slip distribution which places the maximum slip at the center of those events; in practice, of course, slip distributions tend to be fractal [Henry and Das, 2001] and the maximum slip can occur anywhere except at the edge of the rupture.

[26] A further, and perhaps very large, source of error is incomplete knowledge of the slip distributions of the 1797 and 1833 earthquakes. The corals on which those are based come from 14 sites, only 9 of which constrain the 1833 event. Further, and crucially, the southernmost coral is at a latitude of $-3.29^{\circ}$ yet tsunami records suggest that the rupture extended at least as far south as $-5^{\circ}$. Hence, lacking other data, Natawidjaja et al. [2006] assumed that the slip of $18 \mathrm{~m}$ they modeled at $-3.29^{\circ}$ extended southward to about $-5^{\circ}$.

[27] The effect of this assumed high slip is clearly seen in the stress modeling. For instance, three lobes of strongly negative stress due to slip in the 1833 earthquake persist to the present day. The northern two of these correspond to the reasonably well-constrained zone of $11 \mathrm{~m}$ of slip, and they appear to have acted as barriers to the northward propagation of the $2007 M=8.4$ event and may also explain the two distinct patches of slip in the $2007 M=7.9$ earthquake. However, the large negatively stressed area to the south results from the $18 \mathrm{~m}$ of poorly constrained slip described above and it is difficult to understand why the $M=8.4$ earthquake reruptured that area if the stress is so low.

[28] An accurate determination of the stress state is important in assessing the likely slip in a future earthquake in the Mentawai region due to the correspondence between stress and slip. If our current understanding (Figure 4) is correct, then such an event is likely to have little if any slip in the approximately $120 \times 80 \mathrm{~km}$ patch experiencing negative stress. However, if this is inaccurate, then that patch could undergo significant slip. At present, however, we cannot distinguish between these possibilities because of uncertainties in our understanding of the 1833 rupture. Hence, there is a clear need to develop robust techniques for estimating slip from poorly constrained past earthquakes.

[29] Acknowledgments. We thank Roland Burgmann and an anonymous reviewer for helpful comments that improved the manuscript, as well as 


\section{NALBANT ET AL.: COUPLING, STRESS, AND EARTHQUAKE SLIP}

the Editor Andrew Newman for dealing with it so efficiently. This work was partially supported by the Natural Environment Research Council (NE/H008519/1).

[30] The Editor thanks Roland Burgmann and an anonymous reviewer for their assistance evaluating this manuscript.

\section{References}

Bock, Y., L. Prawirodirdjo, J. F. Genrich, C. W. Stevens, R. McCaffrey, C. Subarya, S. S. O. Puntodewo, and E. Calais (2003), Crustal motion in Indonesia from Global Positioning System measurements, J. Geophys. Res., 108(B8), 2367, doi:10.1029/2001JB000324.

Burgmann, R., Kogan, M. G., Steblov, G. M., Hilley, G., Levin, E. V., and E. Apel (2005), Interseismic coupling and asperity distribution along the Kamchatka subduction zone, J. Geophys. Res., 110, B07405, doi:10.1029/ 2005JB003648.

Chlieh, M., J. P. Avouac, K. Sieh, D. H. Natawidjaja, and J. Galetzka (2008), Heterogeneous coupling of the Sumatran megathrust constrained by geodetic and paleogeodetic measurements, J. Geophys. Res., 113, B05305, doi:10.1029/2007JB004981.

Geist, E. L., S. L. Bilek, D. Arcas, and V. V. Titov (2006), Differences in tsunami generation between the December 26, 2004 and March 28, 2005 Sumatra earthquakes, Earth Planets Space, 58, 185-193.

Gomberg, J. S., and M. A. Ellis (1994), Topography and tectonics of the central New Madrid seismic zone: Results of numerical experiments using a three-dimensional boundary-element program, J. Geophys. Res., 99, 20,299-20,310.
Henry, C., and S. Das (2001), Aftershock zones of large shallow earthquakes: Fault dimensions, aftershock area expansion, and scaling relations, Geophys. J. Int., 147, 272-293.

Konca, A. O., V. Hjorleifsdottir, T.-R. A. Song, J.-P. Avouac, D. V. Helmberger, C. Ji, K. Sieh, R. Briggs, and A. Meltzner (2007), Bull. Seismol. Soc. Am., 97, S307-S322, doi:10.1785/0120050632.

Lorito, S., F. Romano, S. Atzori, X. Tong, A. Avallone, J. McCloskey, M. Cocco, E. Boschi, and A. Piatanesi (2011), Limited overlap between the seismic gap and coseismic slip of the great 2010 Chile earthquake, Nat. Geosci., 4(3), 173-177.

Moreno, M., M. Rosenau, and O. Oncken (2010), 2010 Maule earthquake slip correlates with pre-seismic locking of Andean subduction zone, Nature, 467, doi:10.1038/nature09349.

Natawidjaja, D. H., K. Sieh, M. Chlieh, J. Galetzka, B. W. Suwargadi, H. Cheng, R. L. Edwards, J.-P. Avouac, and S. N. Ward (2006), Source parameters of the great Sumatran megathrust earthquakes of 1797 and 1833 inferred from coral microatolls, J. Geophys. Res., 111, B06403, doi:10.1029/2005JB004025.

Newcomb, K. R., and W. R. McCann (1987), Seismic history and seismotectonics of the Sunda Arc, J. Geophys. Res., 92, 421-439.

Subarya, C., et al. (2006), Plate-boundary deformation associated with the great Sumatra-Andaman earthquake, Nature, doi:10.1038/ nature 04522 .

Wells, D. L., and K. J. Coppersmith (1994), New empirical relationships among magnitude, rupture length, rupture width, rupture area, and surface displacement, Bull. Seis. Soc. Am., 84(4), 974-1002. 